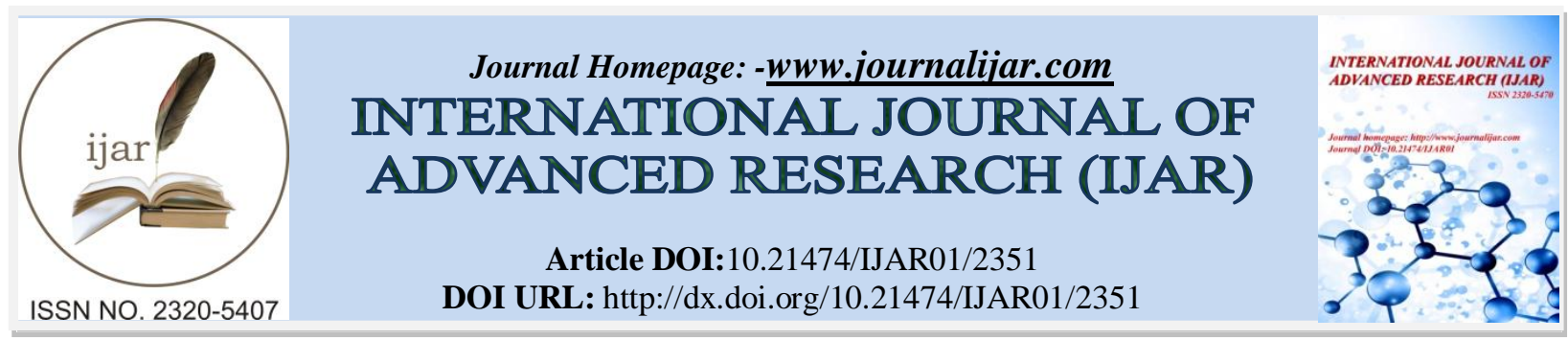

RESEARCH ARTICLE

\title{
ANALYSIS OF VEHICULAR NOISE POLLUTION AT DIFFERENT LOCATIONS IN SRINAGAR TOWN OF (GARHWAL) UTTARAKHAND, INDIA.
}

Dr. Mohan Singh Panwar ${ }^{1}$ and Pallavi Upreti ${ }^{2}$.

1. Associate Professor, Department of Geography, School of Earth Sciences, H. N. B. Garhwal University, Srinagar, Uttarakhand, India.

2. Ph.D. Research Scholar, Department of Geography, School of Earth Sciences, H. N. B. Garhwal University, Srinagar, Uttarakhand, India

\section{Manuscript Info}

(..........................

Manuscript History

Received: 30 September 2016

Final Accepted: 30 October 2016

Published: November 2016

Key words:-

Noise pollution, Health problems,

Srinagar town, Uttarakhand.

\section{Abstract}

Besides growing levels of air and water pollution, road traffic induced noise pollution has been recognized as potential threat to feasible quality of life especially in the urban areas. The accelerated pace of economic development urbanization, and increased vehicular mobility has affected remotest location of India and the Himalayan state of Uttarakhand is no exception to it. The serenity and tranquility for which it's acknowledged globally, is growingly affected by traffic induced noise pollution caused by inflating Pilgrimage/tourism industry, rampant road constructions, encroachment, traffic mismanagement etc. The peak pilgrimage season brings with it uncontrolled traffic influx in the region. All the major pilgrimage towns located on the national Highway from Rishikesh to Badrinath are affected by the vehicular Noise pollution and traffic congestion especially during the holy pilgrimage season. The study tries to evaluate the Noise pollution problem in one of the important towns of Uttarakhand 'Srinagar 'located $105 \mathrm{kms}$ upstream from Rishikesh, on $\mathrm{NH}-58$. Heavy movement of traffic and illegitimate usage of horns is considered main cause of noise pollution in the town which grows irrationally during the yatra season. The average number of vehicular flow was observed to be 890 vehicles/day during the yatra season (May) as compared to 575 vehicles/day during the non yatra season(January). The the average noise intensity levels of the town was recorded to be $70 \mathrm{~dB}$ and noise levels have reached at an alarming stage. It was observed that in $4 / 5$ noise monitoring location, the noise intensity was above the prescribed noisestandard level of Central Pollution Control Board (CPCB), and Bureau of Indian Standard (BIS). The vulnerability to various noise induced health hazards was also very high in the area because the valve of $R$ was 0.78 . 


\section{Introduction:-}

The Himalayan state of Uttarakhand in India is often referred to as the "Abode of Gods". Since ages, it's well acknowledged for its natural beauty, serene spirituality and tranquility, providing immense opportunity for the development pilgrimage/Spiritual tourism and recreational tourism industry.The range of hill stations and pilgrimage centers holds promising future in providing adequate economic returns to the state. However the soaring traffic and noise pollution in the state associated with exponentially inflating tourism industry, rapid industrialization, rampant urbanization and population growthis having a cascading impact on the serenity and peaceful atmosphere of the state. Traffic noise is one of the most immediate and identifiable environmental problem associated with rapid industrialization, urbanization and population explosion.Traffic can be considered as the main source of noise pollution in large cities. (Jamarah et al, 2006). An uncontrolled movement of vehicles in the town creates so called 'traffic jam' and finally creates noise. Vehicle noise mainly arises due to 4 parameters i.e. engine noise, tire noise, blowing horns and nature of roads. The overall vehicular noise is also dependent on the characteristics of the vehicle flow, speed of the vehicles, and condition of the road and traffic management system.

Nowadays, noise pollution is considered as one of the main problems of urban communities which has many hazardous effects on urban environment and may result in a great deal of costs on the society (Martin et al, 2006; Chien and Shih, 2007). Considering the undesirable impact of growing levels of noise on the society and public health it is considered as potential environmental pollutant.Generally high exposure to noise level may cause feeling of annoyance and irritation, damage to auditory mechanisms, number of health related effects like physiological disorders, psychological disorders, disturbance of daily activities and performances, hypertensions and schematic heart diseases (Canter, 1996). The most serious health hazards associated with high level of noise exposure is deafness which initially causes temporary hearing problem while prolonged exposure to high noise level causes permanent hearing damage (Mahesh et al. 2001, WazirAlam et al 2011).Many surveys addressing the problem of noise pollution in many cities throughout the world have been conducted and have shown the scale of discomfort that noise causes in people's lives (Butcha and Vos, 1998; Kura et al., 1999; Ali and Tamura, 2003; Marius et al., 2005). The present study was conducted to assess the level of noise pollution in Srinagar town and its impact on human Health. It also evaluates the vehicular flow using hand held portable sound level meter on selected locations in Srinagar town. The vulnerability of noise induced health hazards was also analyzed using semi structure questionnaire on 5 different locations. The study also tries to suggest the important measure that can be taken to reduce the levels of noise pollution the town.

\section{Study Area:-}

Srinagar is one of the largest towns in Garhwal region of Uttarakhand, located on the left bank of Alakhnanda River at $30.22^{\circ} \mathrm{N}$ latitude and $78.78^{\circ} \mathrm{E}$ longitude.Srinagar is located on one of the busiest national highways in the state NH-58 which links Ghaziabad in Uttar Pradesh near New Delhi with Badrinath andMana Pass in Uttarakhand near Indo-Tibet border. This $538 \mathrm{~km}$ (334 mi) highway starts from Mana village near Indo-Tibet border north of Badrinath temple and passes through Badrinath, Joshimath, Chamoli,Vishnuprayag, Nandaprayag, Karnaprayag,Rudraprayag,Srinagar,Devprayag, Rishikesh, Haridwar, Roorkee, Muzaffarnagar, Khatauli, Meerut, M odinagar andends atGhaziabad near the border with Delhi.Srinagar falling on themain high way remains flooded with vehicles throughout the year especially during the pilgrimage season.

Srinagar served as the capital city of Garhwal region in the $19^{\text {th }}$ century but today it has grown into animportant cultural, commercial and educational Centre. Being placed in central Garhwal at a moderate height, it is an important Valley Bazar in the hill. Expansion in economic activities and growing population demands has increased the transport mobility also. It is well connected to almost all the important destinations in Uttarakhand.Srinagar nagar Palika has current population of 20,115(census 2011) which has drastically grown in terms of numbers and density over the years. The National Highway-58, traversing through the center of the town is often congested causing noise pollution. The condition are severe during the pilgrimage season when the town remains flooded with tourist vehicles leading to hours of traffic jam, disturbing the local traffic movement too. The poor maintenance and development of roads infrastructure, rampant urbanization, road encroachment, and poor traffic regulations further ads to already swollen problem of noise pollution in the town. Consequently the people of Srinagar town are exposed to high levels noise pollution, adversely affecting their health.It was observed that at certain locations the exposure of people to high intensity of noise(more than $90 \mathrm{~dB}$ ) was more than 5 hours. 


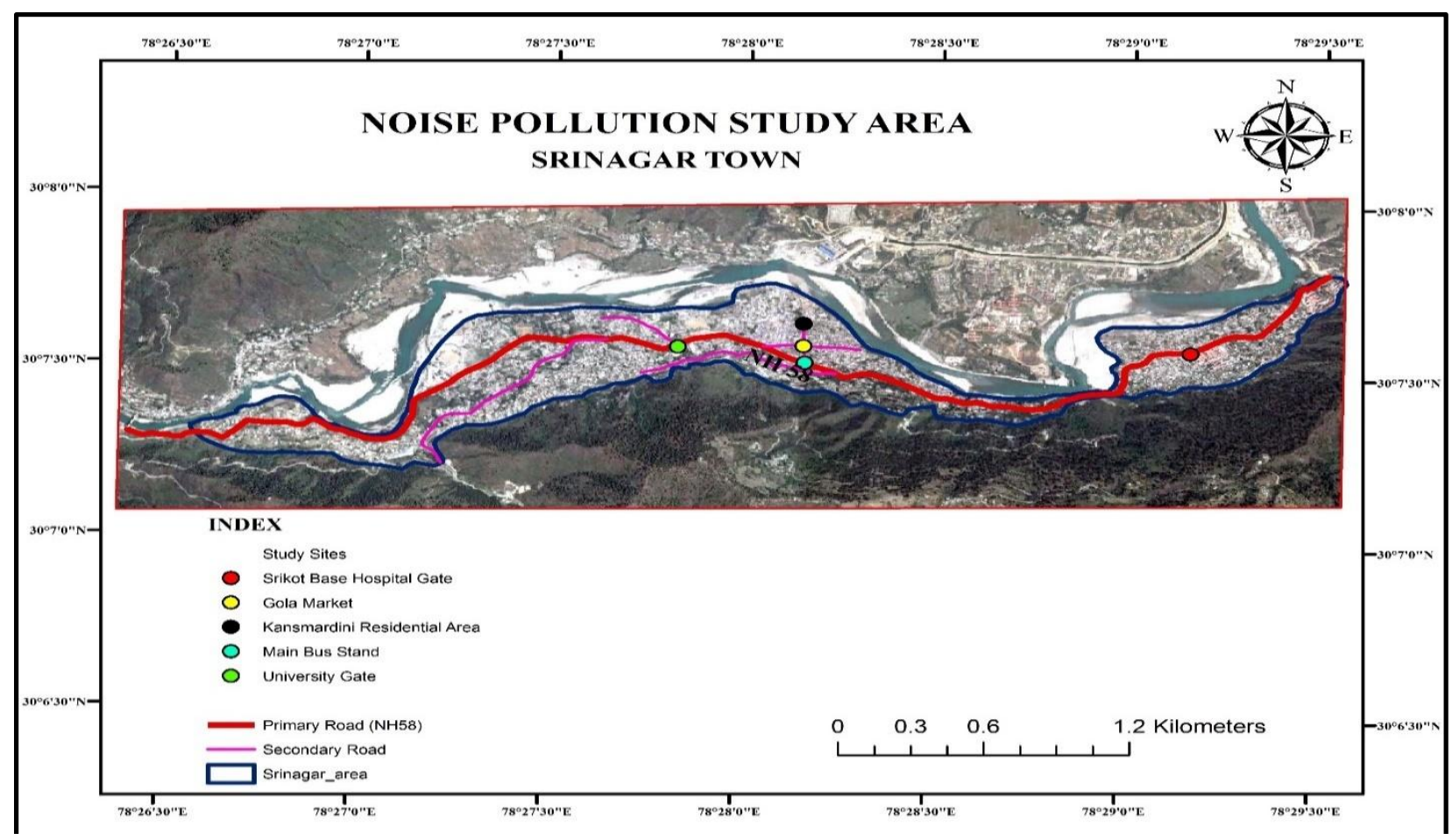

Figure 1:- Noise pollution study sites in Srinagar town in Uttarakhand, (Source: Google earth maps 2014)

\section{Data Base and Methodology:-}

A Noise intensity survey was conducted at different locations of the town for 3 days in a week(Monday, Wednesday, and Friday) during the monthsof January 2016 and May 2016.The data was collected twice in a year mainly to analyze differences in traffic volume and noise levels during the pilgrimage /tourist season(May) and non-pilgrimage/non tourist season (January). After general survey of the town, the Primary and secondary streets were identified and 5 different locations were chosen based on purposive random sampling. Three (3) sites werechosen along the primary street(NH-58) and 2 along the secondary street.The measurement of the noise levels or sound pressure was done using hand held portable sound level meter, which measures sound pressure in dB.(A)i.e.Decibels in A-weighted scale,("A", in Db. (A), denotes the frequency weighting in the measurement of noise and corresponds to frequency response characteristics of the human ear) ranging from, 30-60 for low, 60-90 dB.(A) for medium, 80-110 dB.(A) for higher,100-130 dB.(A) for very high intensity of sound. The sound level measured in $\mathrm{dB}$. is a logarithmic measure of effective sound pressure of at sound relative to standard reference value.

Besides this, open ended questionnaire was prepared to acquire primary information regarding perception of local community towards noise pollution and health vulnerability. Linear regression analysis using SPSS 16 was conducted to analyze health vulnerability to noise pollution in the town. Hundred(100)respondents (20 from each location) based on their exposure to noise were chosen. Careful monitoring of traffic volume/density, types of vehicles, noise levels was done at fixed time intervals(from $9 \mathrm{am}$ to $8 \mathrm{pm}$ ) for each location, for three days in a week i.e. Monday, Wednesday and Friday.For each hour 12 readings were acquired with a gap of 5 minutes and traffic volume was monitored for 10 minutes each hour, then average of each day was taken to calculate the average noise intensity. The satellite image of Srinagar Town has been taken from Google Earth Map 2014, and digitized using ArcGIS 9.1 an ERDAS imagine 9.2 softwares.

\section{Results and Discussions:-}

The noise survey reveals that noise levels of the town are far beyond the satisfactory standards as prescribed by the CPCB (Central pollution control board). The average noise intensity levels of Srinagar town and average traffic flow was observed to be $70 \mathrm{~dB}$ and 590 vehicles/day respectively.In fact at certain places like university gate,Bus stand,and Srikot hospital gate (located along the NH-58) the exposure of people to very high noise intensity (80dB) 
was recorded to be more than 5 hours. The scenario is deterioratingday by day with increasing population density, traffic mismanagement, road encroachment, and poor maintenance of roads in the town.

In the city, excessive noise levels were found especially along the primary streets (Figure-1). Among 5 measurement points, 3 were on primary streets and 2 on secondary roads. Noisevalues were beyond the $65 \mathrm{~dB}(\mathrm{~A})$ on 4 location out of 5 selected sites. On densely crowded roads, the equivalent sound pressure levels can reach up to 75-80 $\mathrm{dB}$ (Yoshida et al., 1997). The average noise intensity of the 3 sites: University Gate (75.7dB),Main Bus Stand(76.3 $\mathrm{dB}$ ), and Shrikot base hospital gate (70.82) (Figure2) located on the primary street N.H-58 were observed to be far beyond the permissible limits.(Figure-3).The noise pollution at the commercial zone near the bus stand exceeds the permissible limit of $65 \mathrm{~dB}$ during the day time. In fact the condition of Srikot hospital gate which falls under silent zone was observed tobe much worst since the noise intensity was measured to be $70.82 \mathrm{~dB}$. (average) despite falling into a silent zone with permissible limit of only $50 \mathrm{~dB}$.( Figure -3,Table-1).

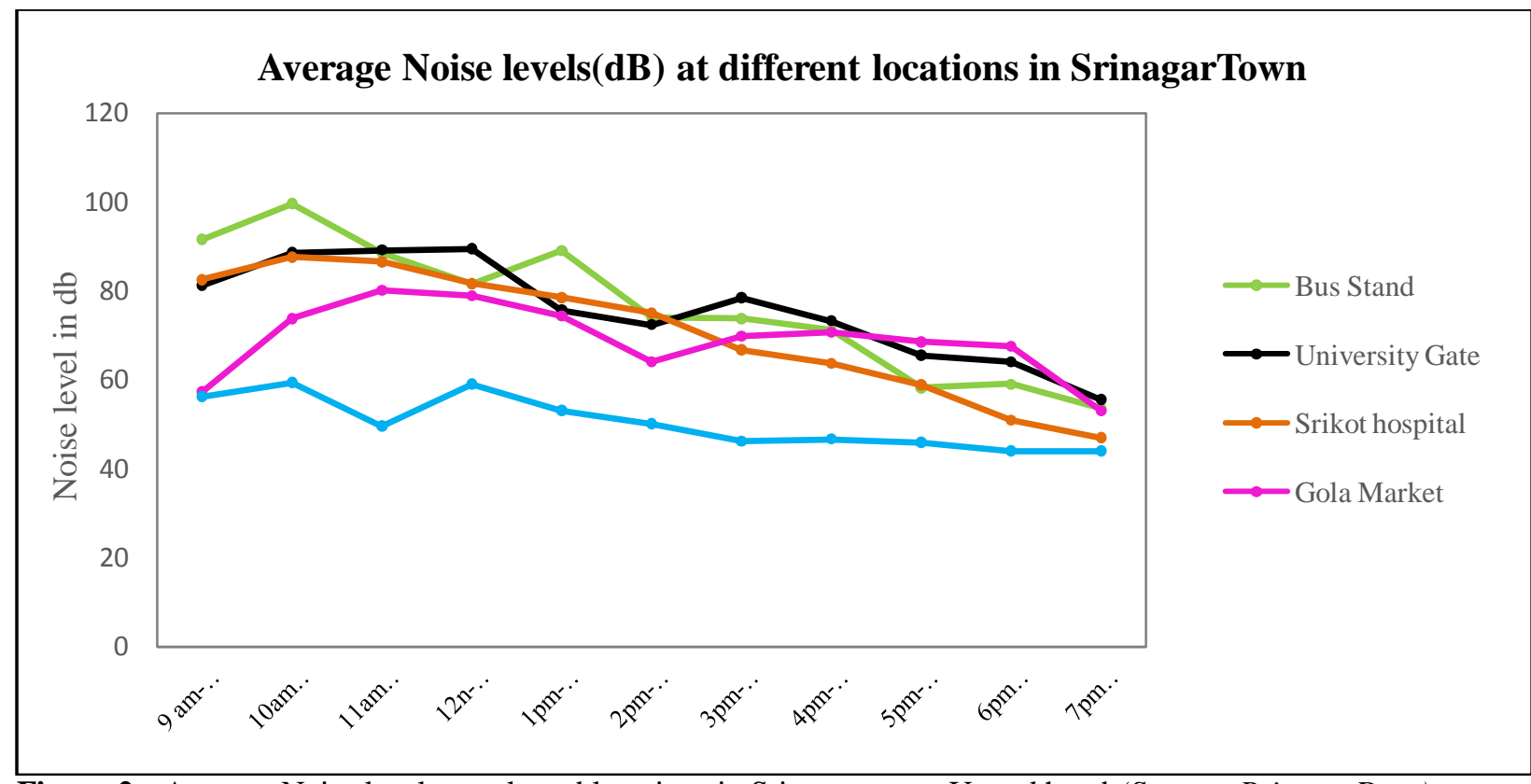

Figure 2:- Average Noise levels at selected locations in Srinagar town, Uttarakhand.(Source: Primary Data)

\begin{tabular}{|c|c|c|c|}
\hline S.no & Category & $\begin{array}{c}\text { Day time } \\
\text { intensity } \\
\text { DB(A) }\end{array}$ & $\begin{array}{c}\text { Night time } \\
\text { intensity } \\
\text { DB(A) }\end{array}$ \\
\hline 1. & Industrial Area & 75 & 70 \\
\hline 2. & Commercial Area & 65 & 55 \\
\hline 3. & Residential area & 55 & 45 \\
\hline 4. & Silent area & 50 & 40 \\
\hline
\end{tabular}

Table 1:-Ambient Air Quality Standards in respect of Noise.(Source: Noise Rules2000, CPCB)

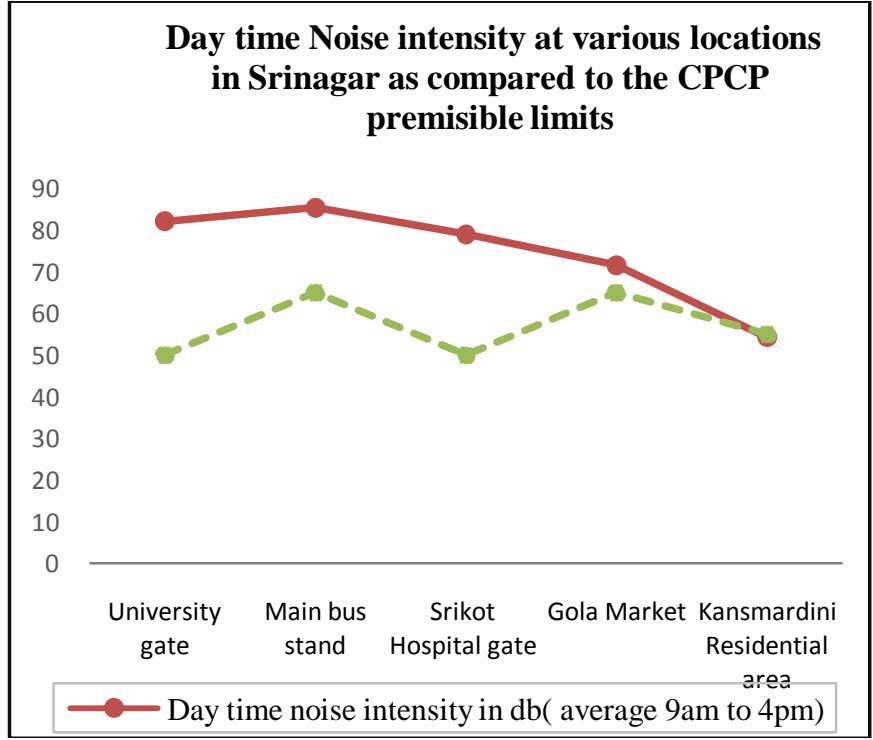

Figure 3:-Daytime noise intensity as compare to CPCB permissible limits 
The vehicular flow and noise intensity at H.B.G.University campus gate located on the National highway-58, is recorded to be very high with $75 \mathrm{~dB}$. during the day time (9-4pm) and above $60 \mathrm{~dB}$ during the evening time (4pm$8 \mathrm{~m}$ ). The heavy vehicular flow is mainly attributed to small 2 wheeler vehicles,and small 4 wheeler congestion during office, school, and college working hours. The highest average noise value $99.6 \mathrm{~dB}$ was determined at the Main bus stand between 10am-11am located along the primary street N.H -58, while the lowest $44.1 \mathrm{~dB}$ (A) was recoded along the Kansmardini residential area on secondary street between $6 \mathrm{pm}-8 \mathrm{pm}$. In fact all the 3 chosen location on primary street 1, i.e. NH-58 recorded very high noise intensity especially during the day time. The bus station of Srinagar was recorded to be immensely high $76 \mathrm{~dB}$, especially during the daytime $(86 \mathrm{~dB})$ due to its location near the main commercial/marketing center of the town: Gola Market, very narrow roads, clustering of busses,mini buses,travelers and vehicular congestions and honking horns. The area remains jammed due to overcrowding of vehicles, narrow roads and traffic mismanagement.

Along the secondary street(Figure-1)the highest noise levels were recorded in central Gola market region, since it the main commercial center of the town, with noise Intensity soaring during morning and evening hours due to multiple economic activities. The market remains congested especially during the late evening hours due to heavy 2 wheeler movement and honking horns.Unlike Gola Market, the Kansmardini Residential areahad comparatively lower vehicular flow and noise intensity, although it is located adjacent to Gola market region. The overall average noise intensity was observed to be $50.39 \mathrm{~dB}$. It was the only site out of 5 selected sites which had noise levels in accordance or below the prescribed limits of CPCB. Since it is a Residential area the day time and Night time,noise intensity was 53.37 and $45.17 \mathrm{~dB}$ respectively.

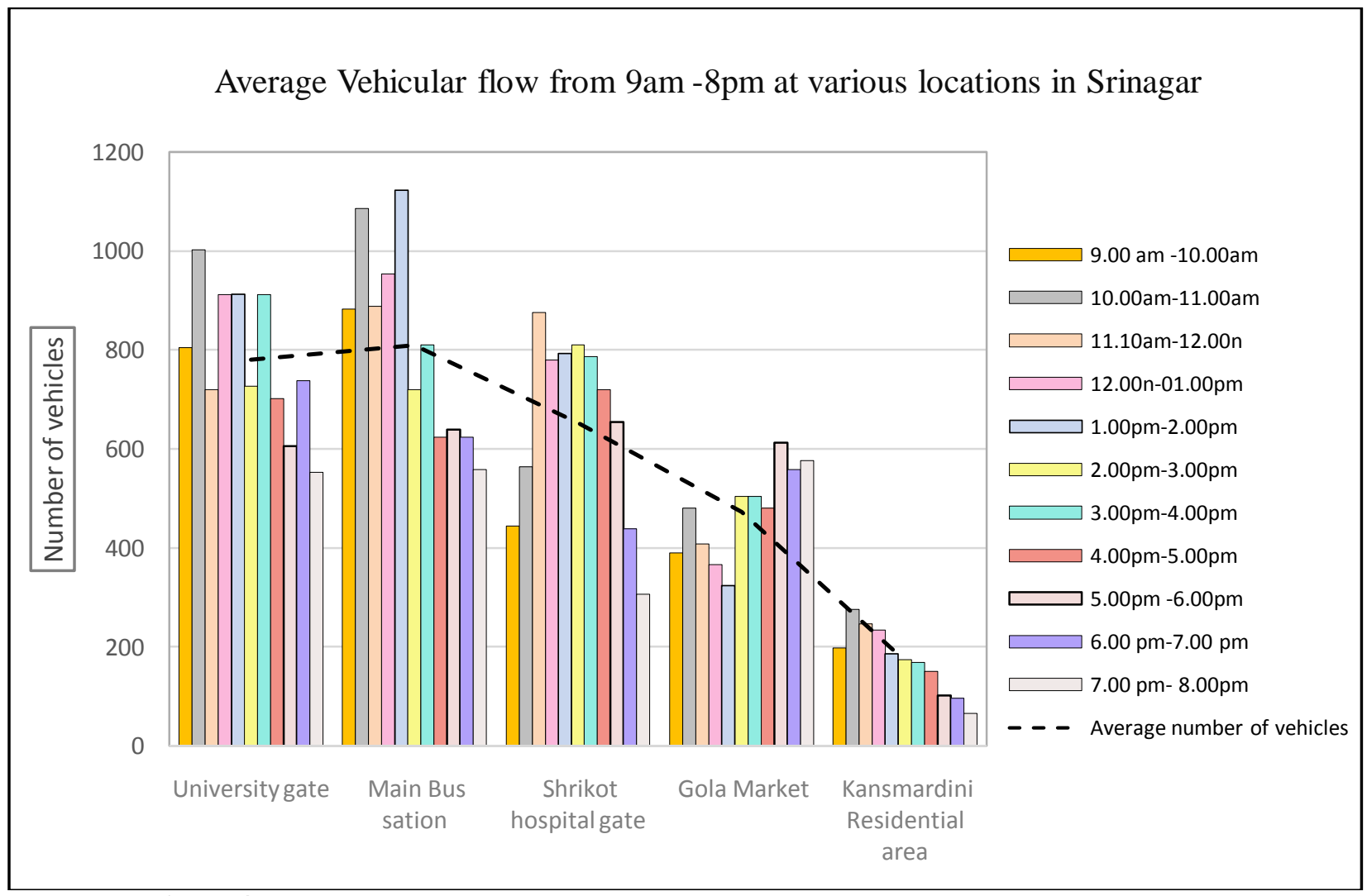

Figure 4:- Average Vehicular flow at various study sites in Srinagar.(Source: Primary data)

Primary Street NH-58 recorded very high intensity of noise levels mainly attributed to heavy traffic movement.The Highest vehicular flow was recorded at Bus stand, with 1086 vehicles passing each hour between 10 am to $11 \mathrm{am}$ and 1122 between $1 \mathrm{pm}-2 \mathrm{pm}$.vehicles. The frequency of 2 wheelers were found to be maximum during morning and evening hours correlating with office,school,and college working hours. H.N.B Garhwal university gate also reflected the same trend with traffic peaking between 9am-11am (1002 vehicles/hour). But the high noise intensity at Srikot Base hospital gate was mainly due to heavy traffic movement since it is located along the busy National 
highway-5.Kansmardini residential area in contrast reflected a low traffic flow of 172 vehicles/day on an average, due to its down town location, and only smalltraffic flow (Figure:4).

\section{Yatra/Pilgrimage season and noise pollution:-}

Yatra season or pilgrimage season is that time period of the year when thousands of devotes from all over India and Beyond Visit 'Chardhams' or 4 most religious places in India. The Chardham sites are Yamunotri, Gangotri, Badrinath and Kedarnathand all four are nestled around snow covered peaks in northern Uttarakhand.National High way-58 is the primary route which carries bulk of yatra traffic to reach Badrinath and Kedarnath shrines.

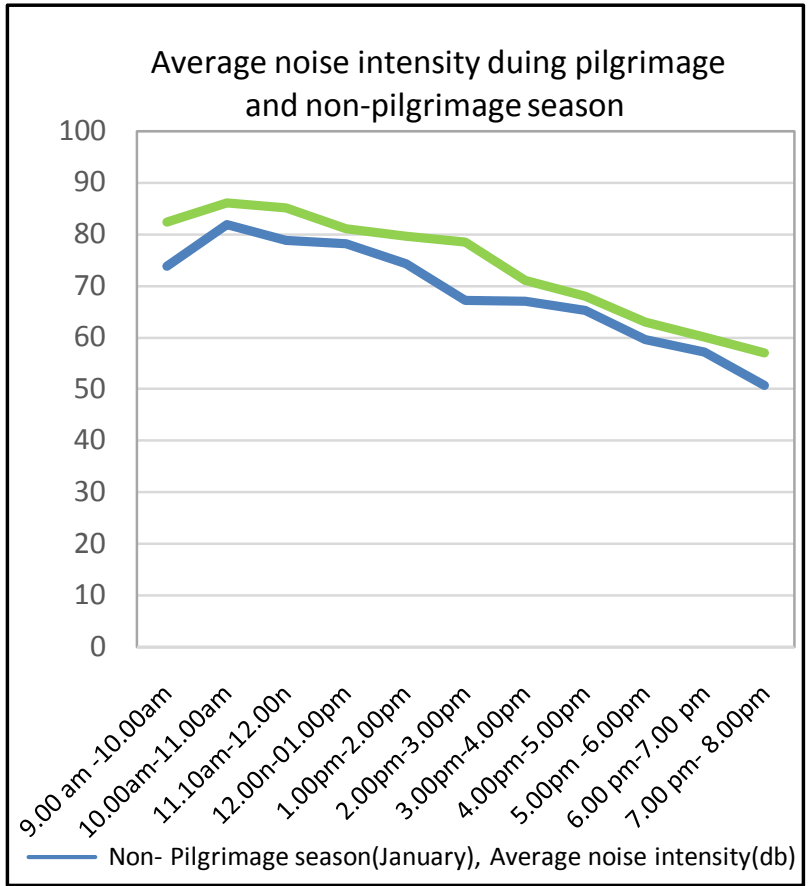

Figure 5:- Variation in noise intensity during Yatra an Non Yatra season (Source: Primary data)

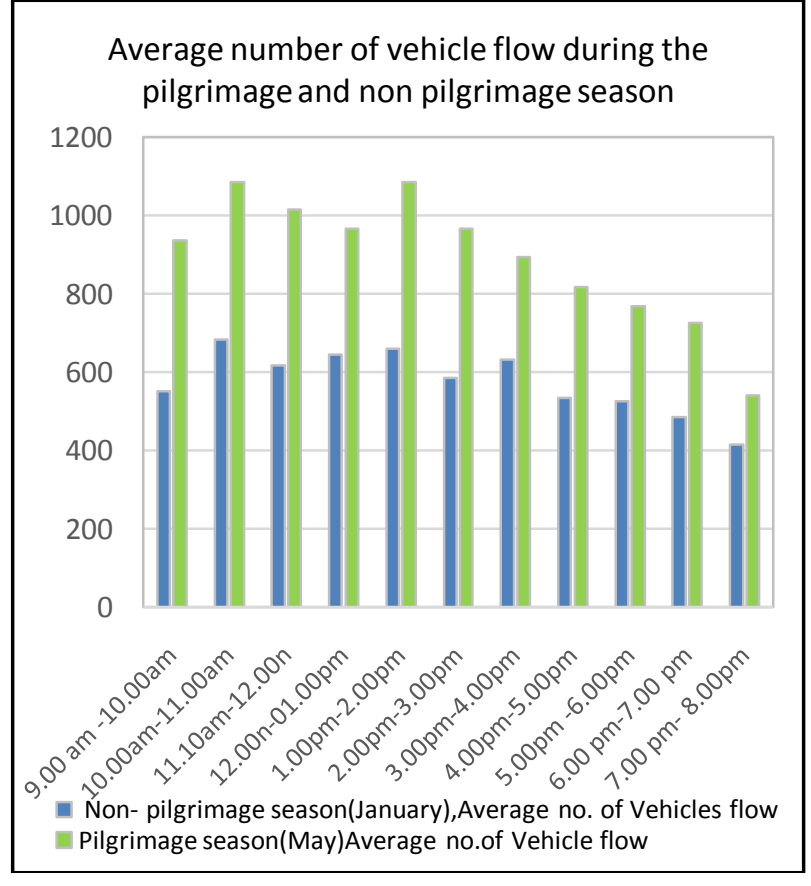

Figure 6:- Variation in Vehicular flow during the Yatra season and Non Yatra season (Source: Primary data)

Therefore the Srinagar town falling along the National highway 58, remains crowded with vehicles during the yatra season. In fact there is a wide variation in traffic flow and noise intensity during the yatra season and other months of the year. The average number of vehicle flow was 890vehicles/day during the yatra season (May 2015) as compared to 575 vehicles/day during the non yatra season(January).The contrast was observed to be very high along the primary streets (NH-58) as compared to the secondary streets. The overall average noise intensity also increased to $73.8 \mathrm{~dB}$ from $68.3 \mathrm{~dB}$ during the yatra season showing an increase of $+5 \mathrm{~dB}$ mainly due to the unrestricted flow of traffic during the peak pilgrimage hours. The day time noise intensity projected maximum contrast of $+6 \mathrm{~dB}$, shooting from $74.3 \mathrm{~dB}$ during non yatra season to $80.5 \mathrm{~dB}$ during Yatra season between $9 \mathrm{am}-4 \mathrm{pm}$.(Figure:5).

Besides the increase in Average noise intensity levels, a tremendous increase in Heavy/Four wheeler traffic flow is also prominent feature of the yatra season in contrast to local 2 wheeler automobiles at other times. The major increase in flow of traffic and increase in noise intensity was recorded along the primary street, because major pilgrimage traffic influx passes through the Major Street NH-58. A maximum of 410 heavy vehicular flow was recorded at the Srinagar Bus Stand (9am to4pm) during the yatra season (May) as compared to 200 vehicles in the month of January. The Gola Market and Kansmardini Residential area located on secondary street were not significantly affected due to increase in traffic inflow during the yatra season (Figure:7) 


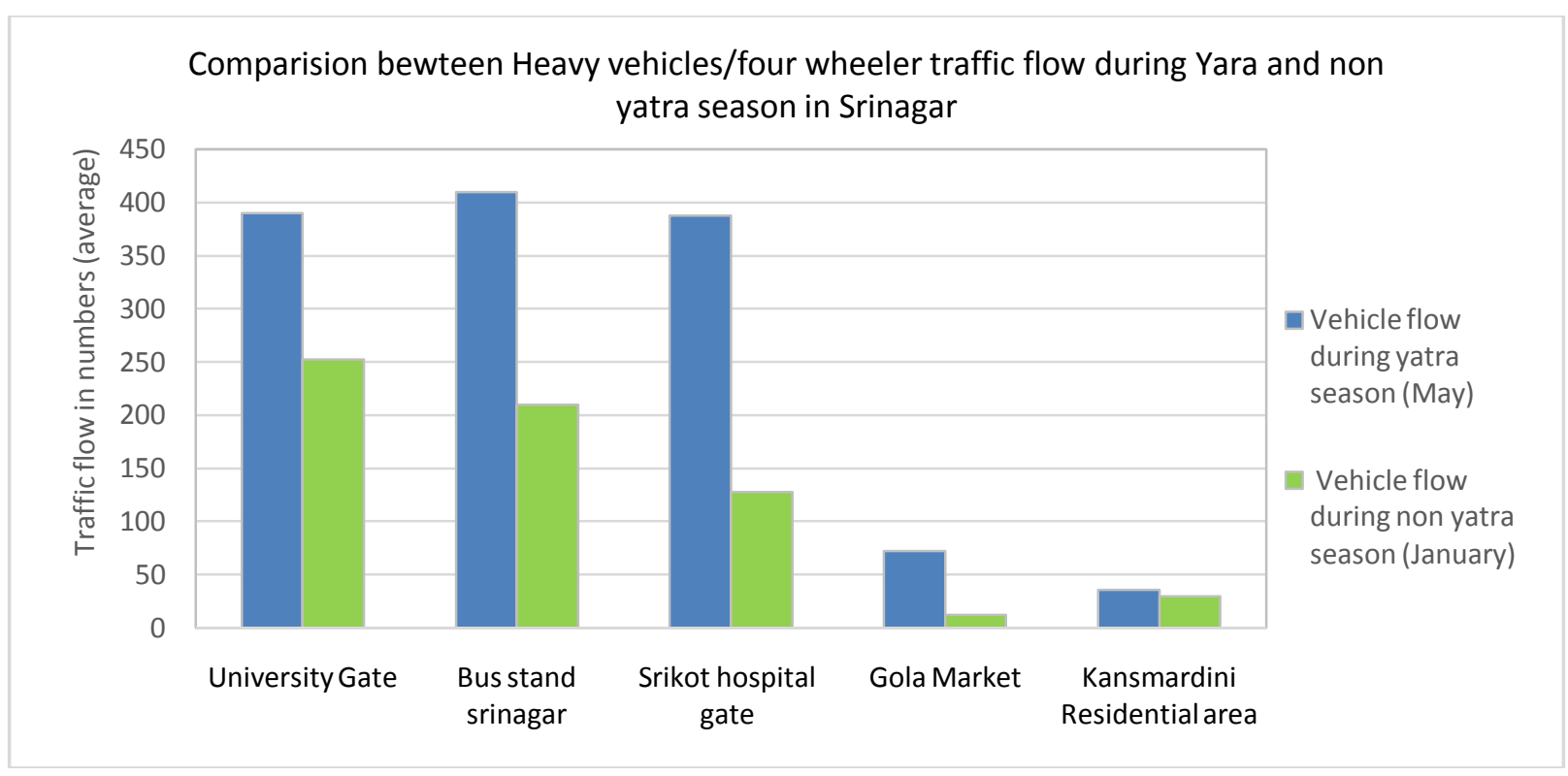

Figure 7:-Variation in Heavy traffic flow during the Yatra Season and Non-Yatra Season.(Source: Primary data)

\section{Noise pollution and health problems:-}

Noise levels recordedin the city, are much higher than the permissible leveland are likely to cause associated health andpsychological illnesses to nearby inhabitant. The trafficcongestion caused by various factors, pollutes the air and produces agents responsible forhealth hazards. The problem of noise pollution remains disguised among other kinds of pollution although it's steadily growing infast developing countries like India. This form of environmental degradation has implication for health as serious as air or water pollution. Studies have proved that a loud noise during peak hours creates tiredness, irritation and impairs brain activities, so as to reducethinking and working abilities. Depending on its duration and volume, the effects of noise on human health and comfort are divided into four categories; physical effects, such as hearing defects; physiological effects, such as increased blood pressure, irregularity of heart rhythms and ulcers ; psychological effects, such as disorders, sleeplessness and going to sleep late, irritability and stress; and finally effects on work performance, such as reduction of productivity and misunderstanding what is heard (Job,1996; Evans and Hygge, 2000; Stansfeld et al., 2000; Passchier-Vermeer and Passchier, 2000; Quis, 2001;Marius, 2005).

The survey conducted on 100 random people revealed that intensity of health problems are soaring with growing exposure of people to noise pollution. $90 \%$ of respondents blamedincreasing noise pollution tobe major cause of headache,irritation, annoyance, insomnia.Uninterrupted sleep is known to be a prerequisite for good physiological and mental functioning in healthy persons. It affects the sleep there by inducing the people to become restless and lose concentration and presence of mind during their activities. (Singh D.et.at, 2010).Apart from various effects on sleep itself, noisepollution during sleep causes increased blood pressure, increased heart rate, increased pulse amplitude, vasoconstriction, cardiac arrhythmias and increased body movement. Secondary effects include fatigue, depressed mood and well-being and decreased performance. (Lad R.J, 2011). Noise can cause irritation,which results in learning disabilities in children and restlessness among adults. Annoyance increases significantly when noise is accompanied by vibration or by low frequency components. Long exposure to high sound levels can cause loss of hearing especially among infants and children.Hearing damage is related to duration and intensity of noise exposure and occurs at levels of $80 \mathrm{~dB}$ or greater, which is equivalent to the noise of heavy truck traffic.

Noise can change men's physiological state by speeding up pulse and respiratory rates. It causes pain, ringing in the ears, feeling of tiredness, thereby effecting the functioning of human system. $60 \%$ people linked reduced work efficiency and mental alertness to increasing exposure to high intensity of noise. Acute exposure to noise activates nervous and hormonal responses, leading to increased blood pressure and heart rate and to vasoconstriction. If the exposure is of extreme intensity, there is an increase in heart rate and peripheral resistance an increase in blood pressure and increased levels of stress hormones. (Bhagwat.et.al 2013)Noise above $80 \mathrm{~dB}$ is consistently associated 
with decreased helping behaviour and increased aggressiveness (Juang D. F, et.al, 2010). Therefore consistent exposure to high noise intensity may also alter Social behaviour and interaction.

\section{Local people response on exposure to noise pollution and health problems}

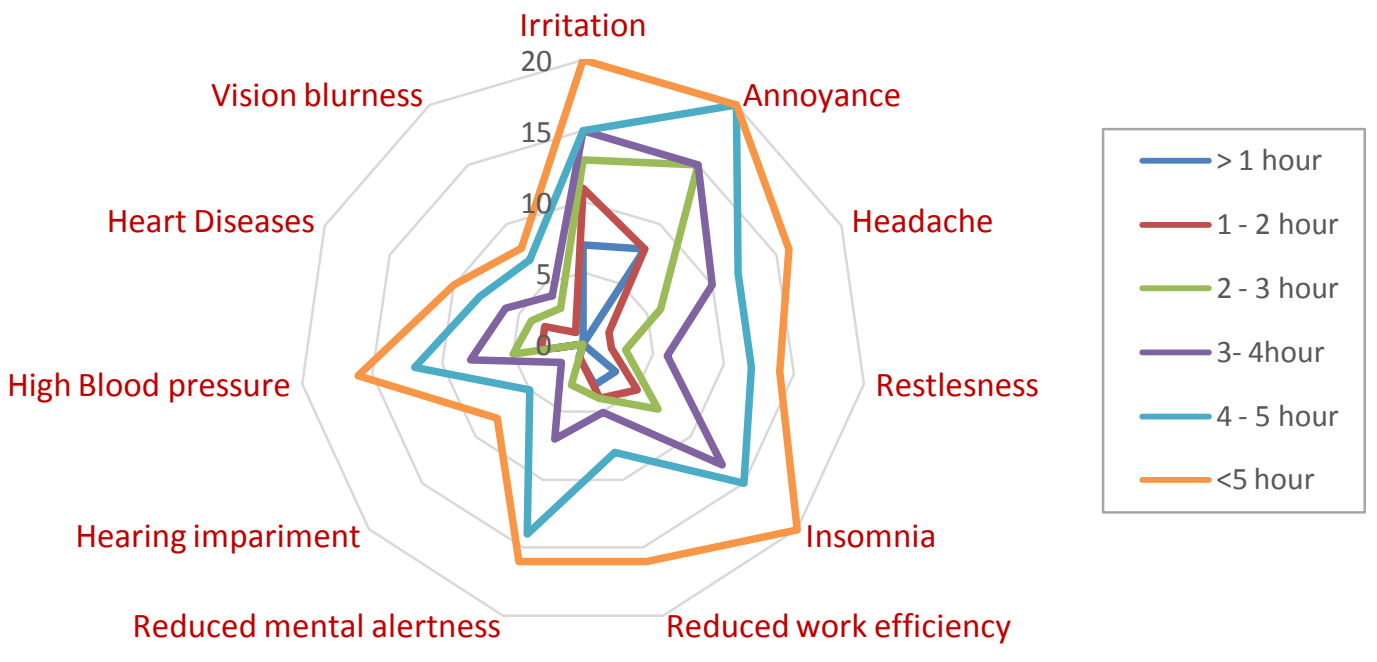

Figure 8:- Exposure to noise pollution and health problems.(Source: Primary data)

An increase in trend between hours of exposure to noise pollution and health problems can be seen in the area. (Figure-8). People with more than 3 hours of exposure to high intensity of noise, were more vulnerable to noise induced health hazards.100\% people with 4-5 hours of exposure to noise pollution complained about insomnia, Annoyance and Headache. Increasing blood pressure, problems of hearing impairment are also growing with more exposure of people to noise pollution.(Figure-8).

\begin{tabular}{|c|c|c|c|c|}
\hline Model & $\mathbf{R}$ & $\mathbf{R}^{2}$ & Adjusted R Square & Std. Error of the Estimate \\
\hline 1 & 0.78 & 0.60 & 0.56 & 2.21 \\
\hline
\end{tabular}

Table 2

A very high positive correlationexist between the level/degree of exposure to noise pollution and probability of health problems in the area because $\mathrm{R}$ is 0.78 . There is constant increase in intensity of various health ailment with increasing exposure of people to noise pollution because $R^{2}$ is 0.60 and adjusted $R^{2}$ is 0.56 with standard error of 2.21 (Table:2). The people exposed for more than 4 hours to high noise intensity exhibit highest degree of positive correlation of $(.81)$ to various health ailments.

\section{Conclusion:-}

This research paper elucidates that noise pollution has reached higher levels even in small sized river valley Town of Srinagar in Uttarakhand.The measurements of noise levels have been recorded at the different sites: Silent, Residential and Commercial zones of the city. The analysis has revealed that noise pollution levels are rather higher than prescribed noise standards in 4/5 examined sites: H.N.B. Garhwal University Gate,Srinagar Main Bus Stand,Srikot Hospital Gate, and Gola Market. Since Srinagar is located along the National Highways -58 which is the lifeline of Garhwal Himalayas and major pilgrimage routes linking Major Holy Shrines, therefore the town pertains to have higher levels of Noise pollution. The uncontrolled influx of tourist vehicles especially during theyatra season and poor traffic management remains one of the major reasons for chaos, jams and noise pollution in the town. Honking by youngsters especially in 2 wheelers was also observed to be prominent reasons in the area especially in the Gola Market and University Gate region. Imparting necessary information and public awarenessthrough social media,Newspapers,radios,social gatherings is essential to highlight the effects of Noise pollution.Stringent traffic rules against Honking/use of horn and strong traffic management is also important to manage the situation of noise pollution. Regular monitoring of pollution, checking road encroachments, is also important to maintain hassle free 
traffic flow and to reduce traffic jam induced noise. Organising 'Anti-honk campaigns' can also play indispensable role in cutting down unnecessary honking byspreading awareness especially among the youngsters. Strong Legislation,determined enforcement, disciplined development of technical methods to control noise is imperative for healthy and noise free society in river Valley town of Srinagar.

\section{References:-}

1. AlamWazir, (2011) GIS based assessment of noise pollution in Guwahati city of Assam, India, International Journal of Environmental Sciences, Vol 2, No.2.

2. Agarwal S. and Swami B.L,(2010). Status of ambient noise levels in Jaipur City, Environ. Conser. J.,11(1, 2), 105-108.

3. Chauhan Avnish, Panwar Mayank, et.al, (2010). Assessment of noise level in different zones of Haridwar City, Uttarakhand, Researcher Vol.2(7):56-59.

4. DevPramendra, (2011), Environmental Noise Pollution Monitoring and Impacts On Human Health in Dehradun City, Uttarakhand, India.Civil and Environmental Research, Vol 1, No.1.

5. Juang D. F., Lee C. H., Yang T., Chang M. C., (2010). Noise pollution and its effects on medical care workers and patients in hospitals, Int. J. Environ. Sci. Tech., 7 (4), 705-714.

6. Bhagwat P.H. and Meshram Pramod M., (2013)Study of noise pollution during GaneshUtsav in Yavatmal City, Int. J. Pharma.Chem. Sci., 2 (1), 496-498.

7. Keerthana1, Gobinath.R, NeelimaSinghvi, Chitravel.V, Saranya.S, Kannan.T,(2013), An Analysis of noise pollution in Tirupur city Scholars Journal of Engineering and Technology,Vol.1(3):pp.154-168.

8. Kumar Nikhil, James Abhishek, et,al.( 2013). Study on Noise Pollution level in Parks of Allahabad City, India, International Research Journal of Environment Sciences, Vol. 2(8), 88-90.

9. Lad R. J., Patil V. N. and Raut P. D., (2011),Studyof noise pollution during Deepawali festival in Kolhapur City of Maharashtra, India, Ind. Streams Res. J., 1 (7), 82.

10. Ozer S, Yilmaz H, Yeil M, and Yeil P,(2009), Evaluation Of Noise Pollution Caused By Vehicles In The City Of Tokat, Turkey,Scientific Research and Essay, Vol.4 (11), pp. 1205-1212.

11. PadhyP.K,AndPadhi B.K (2008), Centre Assessment Of Noise Quality In BolpursantiniketanAreas (India) Journal of Environmental Research and Development Vol. 3 No. 1,

12. Sampath S., Murali S., et.al. (2004). Ambient noise levels in Major Cities in Kerala, J. Ind. GeophysUnion, Vol.8, No.4, pp.293-298

13. Singh D, Kaur A,(2013) Study of Traffic Noise Pollution at different location in Jalandhar City, Punjab, IndiaInternational Journal of Environmental Sciences and Research,Vol. 2, No. 2, pp. 135-139. 